\title{
Questionable All Along, DNA's Inheritance Role Is Now Failing in a Big Way-Does Anyone Care?
}

\author{
Ted Christopher \\ 71 Azalea Road, Rochester, NY, USA \\ Email: tchrist7@rochester.rr.com
}

How to cite this paper: Christopher, T. (2022). Questionable All Along, DNA's Inheritance Role Is Now Failing in a Big WayDoes Anyone Care? Open Journal of Philosophy, 12, 29-53.

https://doi.org/10.4236/ojpp.2022.121003

Received: December 21, 2021

Accepted: February 8, 2022

Published: February 11, 2022

Copyright $\odot 2022$ by author(s) and Scientific Research Publishing Inc. This work is licensed under the Creative Commons Attribution International License (CC BY 4.0).

http://creativecommons.org/licenses/by/4.0/ (c) (i) Open Access

\begin{abstract}
Science's theory of evolution purports to explain life and its historical dynamics in a physics/material-only fashion. But this entails a broad reliance on DNA (deoxyribonucleic acid) for inheritance (and thus blueprints), which appears to be implausible for a number of unusual innate behaviors. The immediate unfolding challenge, though, is that the inheritance role is conveniently testable via searches for the DNA origins of a number of human behavioral and health tendencies, and despite enormous efforts those searches have thus far largely failed (i.e., the "absolutely beyond belief" missing heritability problem). This existing case for DNA's inadequacies will be briefly reviewed herein. The subsequent main analysis considers some big challenges facing DNA associated with some evolutionary dynamics-the acquisition of color vision in primates; instinctive behaviors including the egg-laying practices of emerald jewel wasps; kin selection; and our natural religious beliefs. Together these challenges strongly suggest that the acceptance of DNA as the (complete) language of life was premature. The haphazard and ambiguous nature of DNA/genetic specifications is very unlikely to have provided a vehicle for the exacting blueprints required for the many instinctive behaviors or capacities. Life appears to be more complex than biologists believe. Two possible alternative explanations are briefly considered in the wake of these discussions. Finally, does anyone-beginning with academics-care about this unfolding foundational failure?
\end{abstract}

\section{Keywords}

Evolution, Genetics, Behavioral Genetics, Scientific Materialism, Reincarnation, Morphic Resonance

\section{Introduction: Biology's Vision for DNA}

There are enormous expectations placed on deoxyribonucleic acid (DNA). It's 
essential to science's molecular-only vision of life and the associated modern intellectual purview. The psychologist Steven Pinker in an essay introduced that vision in stating that:

In making sense of the world, there should be few occasions in which we are forced to concede "It just is" or "It's magic" or "Because I said so". The commitment to intelligibility is not a matter of brute faith, but gradually validates itself as more and more of the world becomes explicable in scientific terms. The processes of life, for example, used to be attributed to a mysterious elan vital; now we know they are powered by chemical and physical reactions among complex molecules (Pinker, 2013).

The presumed director of those complex molecules is of course DNA. Consistent with this, Pinker went on to add that science's "understanding consists not in a mere listing of facts, but in deep and elegant principles, like the insight that life depends on a molecule that carries information, directs metabolism, and replicates itself" (Pinker, 2013).

Consistent with this the pioneering geneticist Craig Venter answered the question "What is life?" with the expression, "DNA-driven biological machines" (Venter, 2014: p. 6). Also Venter in his 2007 book, A Life Decoded: My Genome: My Life, extrapolated that vision in practical fashion to declare that the Human Genome Project:

Has charted a landscape in which we will discover the most intricate workings of our species, the particularities of our own individual genetic makeup, and the promise of novel approaches to health and medicine that will mark a new stage in human development, one in which inherited biology is no longer destiny (Venter, 2007, inside cover).

The biologist Richard Dawkins characterized our genomic nature with "DNA neither cares nor knows. DNA just is. And we dance to its music" (Venter, 2014: p. 1). Likewise in What Evolution Is, the late prominent biologist Ernst Mayr at no point suggested any doubt that DNA can fulfill its many inheritance roles. Additionally Mayr pointed out, "[o]ne can never fully understand the process of evolution unless one has an understanding of the basic facts of inheritance, which explain variation" (Mayr, 2001: p. 89). That presumed inheritance role is equivalent to the common assumption that DNA provides the conception-beget blueprints for an organism.

Additionally, readers can get a further practical take on this situation via some statements provided by the Nobel laureate James D. Watson. In a 2003 interview with him, Scientific American asked how much "is left for us to do" after having "largely worked out" the human genome? After some speculation about the possible significance of epigenetic phenomena (secondary modifying factors beyond the actual sequence of DNA elements) Watson replied:

[relevant research] seems to moving pretty fast. You don't really want to make a guess, but I'd guess that over these next 10 years, the field will be 
pretty played out. A lot of very good people are working on it. We have the tools. At some stage, the basic principles of genetics will be known be in terms of gene functioning, and then we'll be able to apply that more to [the really difficult] problems such as how the brain works (Watson, 2003).

Next, when Scientific American asked Watson, "[i]f you were starting out as a researcher now", Watson interjected, "I'd be working on something about connections between genes and behavior. You can find genes for behaviors...". The term "field" in the above quote which was to "play" itself out, most likely included both behavioral genetics and personal genomics which reflect our particular individual behavioral and health tendencies, respectively.

Additionally, a significant aspect of the contemporary scientific mindset was also suggested by Watson in his self-characterization:

I was born curious....And so if you wanted an explanation for life, it had to be about the molecular basis for life. I never thought there was a spiritual basis for life; I was very lucky to be brought up by a father who had no religious beliefs (Watson, 2003).

And in commenting on a promotional line used for the genetics-inspired movie Gattaca- "There is no gene for the human spirit" - Watson wrote, "[i]t remains a dangerous blind spot in our society that so many wish this were so" (Watson et al., 2017: p. 440).

On a similar note, Steven Pinker had written:

[ $\mathrm{t}$ ]here is no such thing as fate, providence, karma, spells, curses, augury, divine retribution, or answered prayers-though the discrepancy between the laws of probability and the workings of cognition may explain why people believe there are.

Beyond this sweeping dismissal of materialism-challenging phenomena, Pinker went on to directly characterize the contemporary default intellectual dismissal of religions with:

[t]he moral worldview of any scientifically literate person-one who is not blinkered by fundamentalism-requires a radical break from religious conceptions of meaning and value (Pinker, 2013).

Readers should keep in mind Watson's and Pinker's (and more generally contemporary science's) materialist fixation and the associated dismissal of religious/alternative perspectives.

This paper will first consider the last decade and a half or so of significant updates from efforts to tie genetic variations to observed variations in our own behavioral and disease manifestations (in the scientific vernacular, connecting genotypes to phenotypes). Next, some particular human behavioral challenges to genetic reasoning (and materialism) will be considered. Next, the main portion of the analysis will consider the plausibility of DNA's role in some evolutionary phenomena-including the acquisition of color vision in primates; instinctive 
behaviors including the egg-laying practices of emerald jewel wasps; kin selection; and also our natural religious beliefs. Finally, some perspectives on these observations will be provided along with brief consideration for two alternative explanations.

A reminder here is that "gene" denotes a subset of DNA which provides a template for the construction of the body's protein molecules, "genome" denotes the collection of an individual's genes (and sometimes loosely as the whole DNA molecule).

\section{DNA Searches and Outcomes}

Some aspects of our individual differences along with DNA's presumed heritability role can be inferred from human studies. This connection was neatly captured by Steven Pinker when he wrote:

schizophrenia is highly concordant within pairs of identical twins [about $50 \%$ of the time when one is affected so is the other twin], who share all of their DNA and most of their environment, but far less concordant within pairs of fraternal twins, who share only half of their [variable] DNA...and most of their environment. The trick question could be asked-and would have the same answer-for virtually every cognitive and emotional disorder or difference ever observed. Autism, dyslexia, language delay, language impairment, learning disability, left-handedness, major depressions, bipolar illness, obsessive-compulsive disorder, sexual orientation, and many other conditions run in families, are more concordant in identical than in fraternal twins, are better predicted by people's biological relatives than by their adoptive relatives, and are poorly predicted by any measurable feature of the environment (Pinker, 2002: p. 46).

So it appears that many of our variations in behavioral and health inclinations appear to follow biological parent-connected patterns. While variations in behavioral innateness are often obvious (in particular to parents), the inheritancepackaging of that innateness is not so clear (unlike with physical features). This packaging connection, though, has become more apparent through formal studies. Pinker's statement, though, does appear to shortchange environmental contributions to schizophrenia (Balter, 2017).

A significant point here is that even if an individual's innate traits weren't established at their conception, they should then be largely specified by some postconception mutations. Our innate aspects aren't supposed to occur as a result of "magic", they are supposed to be based on specific DNA/genetic origins.

Turning towards outcomes, fourteen years after predicting wholesale genetic success within a decade, James D. Watson in his book, DNA: The Story of the Genetic Revolution, broke from that earlier optimism and acknowledged in particular the lack of genetic insight into the occurrences of mental illnesses. Watson pointed out that " $[\mathrm{t}]$ he history of this research is full of high hopes brought low" (Watson, 2017). He also provided a fitting quote on the situation from the 
geneticists Neil Rich and David Botstein:

[t] he recent history of genetic linkage studies for [manic depression] is rivaled only by the course of the illness itself. The euphoria of linkage findings being replaced by the dysphoria of non-replication [in other populations] has become a regular pattern, creating a roller coaster-type existence for many psychiatric genetics practitioners as well as interested observers.

Sober assessments also showed up in a 2017 Scientific American article by Michael Balter, “Schizophrenia's Unyielding Mysteries: Gene Studies Were Supposed to Reveal the Disorder's Roots. That Didn't Happen. Now Scientists Are Broadening the Search" (2017). After enormous efforts to identify the expected DNA basis for the presumed inherited susceptibility to the profound condition schizophrenia, insiders provided some frank appraisals. These included the geneticist David Goldstein's comment that "[p]eople working in the schizophrenia genetics field have greatly over-interpreted their results" and further that they should utilize "a whole lot more humility". Additionally, the behavioral geneticist Eric Turkheimer offered the noteworthy, "GWAS [Genome Wide Assessment Studies] shows that schizophrenia is so highly, radically polygenic [i.e., with many DNA contributors] that there may well be nothing to find, just a general unspecifiable genetic background".

Does this really make sense? A profound, focused, and presumed DNA-based condition like schizophrenia is somehow the result of many, many individual genetic contributions; thus contradicting the existing logic of identified disorders with their correlations with strong (singular) genetic contributions?

Continuing, significantly it turns out that homo sapiens have been referred to by geneticists as a "small species" since there is relatively little genetic variation amongst us and such limited variation is typical of a species with a small population (this follows from our historical passage through a very tight population bottleneck) (Pinker, 2002: pp. 142-143). As a result any two human beings are roughly $99.9 \%$ identical in terms of their DNA blueprints, which translates to only being different in about 3 million bases or letters (Green, 2013; Kingsley, 2009; Schafer, 2006). Thus, with this limited amount of variation present in our genomes, genetic searches were anticipated to be well positioned to identify critical genetic variants as reflected in Watson's earlier prediction.

One of the first big public acknowledgments of genetic search failures came in 2008. At that time Duke University's geneticist David Goldstein was quoted regarding the outcome of the just completed, thorough (or "tour de force") comparisons between the million or so common genetic variations and the inheritance patterns associated with the occurrences of common complex diseases (some of which overlap into the behavioral domain) (Wade, 2008). It was naturally expected that some of these common variations in our DNA blueprints would be correlated with the patterns of complex disease susceptibility. And yet, despite this, Goldstein pointed out: 
[a]fter doing comprehensive studies for common diseases, we can explain only a few percent of the genetic component of most of these traits. For schizophrenia and bipolar disorder, we get almost nothing; for Type 2 diabetes, 20 variants, but they explain only 2 to 3 percent of familial clustering, and so on.

Goldstein then added:

It's an astounding thing that we have cracked open the human genome and can look at the entire complement of common genetic variants, and what do we find? Almost nothing. That is absolutely beyond belief.

Note that "common" here implies that a given specific genetic variation is present in at least 5 percent of humans.

That failure to confirm the common variants theory was also echoed in a 2010 Scientific American article, "Revolution Postponed" (Hall, 2010). Another critical appraisal also came in 2010 in which Jonathan Latham and Allison Wilson of the Ithaca, New York's Bioscience Resource Project pointed out that with few exceptions (including previously identified genes for cystic fibrosis, sickle cell anemia, and Huntington's disease; and also including genetic contributions for some instances of Alzhemier's and breast cancer):

according to the best available data, genetic predispositions (i.e. causes) have a negligible role in heart disease, cancer, stroke, autoimmune diseases, obesity, autism, Parkinson's disease, depression, schizophrenia and many other common mental and physical illnesses that are the major killers in Western countries (Latham \& Wilson, 2010).

Lathan and Wilson went on to ask (in italics) "[ $h]$ ow likely is it that a quantity of genetic variation that could only be called enormous (i.e. more than $90 \%-95 \%$ of that for 80 human diseases) is all hiding in what until now [circa 2010] had been considered genetically unlikely places?". Furthermore, Latham and Wilson also suggested that "[b]y all rights then, reports of the GWA [genome wide assessments] results should have filled the front pages of every world newspaper for a week". At a minimum this unfolding situation deserved much more attention.

Starting in 2018, though, a new more thorough approach appeared to produce some successful searches. The basic idea was that the missing genetic contributions were likely in such tiny doses that to detect significant overall genetic influence, it is necessary to look more fully at genomes and also utilize more individuals' DNA. The requisite count of individuals was believed to be in the hundreds of thousands. The resulting processing then allowed researchers to piece together a large summation formula that could be used to predict the overall genetic contribution for an individual's particular trait, given the specification of thousands of relevant genetic variants. Thus, the genome-wide polygenic score (GPS) was then supposed to reflect the cumulative influence of many trait-associated, mostly 
minute, genetic contributions.

Some of these studies claimed to have identified genetic origins for roughly 10 percent of the variation in individuals' educational attainment (Lello et al., 2018; Lee et al., 2018; Allegrini et al., 2019; Plomin \& Stumm, 2018). Furthermore, some of these studies also attempted to piggyback searches for the genetic origins of cognitive performance onto the educational attainment analysis (Lee et al., 2018; Allegrini et al., 2019; Plomin \& Stumm, 2018). Due to correlations that have been observed between educational attainment and intelligence, it is thought that you can begin to estimate DNA's contributions to IQ by using educational attainment analysis.

As it turned out, though, in 2019 complications with these polygenic scorebased studies were encountered. Some earlier studies had attempted to uncover the genetic dynamics underlying the fact that northern Europeans tend to be taller than southern Europeans. These initial analyses appeared to be successful. Two later works in applying those findings to the larger and relatively unstructured UK Biobank data set, though, did not corroborate this (Berg et al., 2019; Sohail et al., 2019). In particular they contradicted the claimed genetic basis for northern Europe's taller populations. One of the papers pointed out that the small presumed genetic contributors which constitute:

large numbers of [variants] below genome-wide [statistical] significance are extremely sensitive to biases due to uncorrected population stratification. More generally, our results imply the typical constructions of polygenic scores are sensitive to population stratification... (Sohail et al., 2019).

Population stratification refers to specific evolution-beget mutations that different groups have separately acquired (producing what might be considered genetic fingerprints for groups). The presence of such genetic markers might facilitate identifying an individual's genealogy, but it is not likely to contribute to predicting their traits (or phenotypes).

Based on these two contradictory study findings an April 2019 Genomics article, "New Turmoil Predicting the Effects of Genes" was produced (Cepelewicz, 2019). That article suggested that the polygenic successes thus far had been unknowingly distorted by population stratification. One researcher, Nick Barton of the Institute of Science and Technology Austria, said:

[t]he whole thing is tricky, because the origins of genetic variation in any population are really complicated. Now you really can't take at face value any of these methods over the last four or five years that use polygenic scores.

One researcher, Shamil Sunyaev of Harvard Medical School, commented that "no one realized how big of a problem" the population stratification phenomena is. Another researcher commented that "[i]t's fairly humbling to see all of that work go away".

In considering the heritability situation here one additional study is of partic- 
ular note. That study involved another big polygenic score effort in this case trying to make DNA sense about the occurrences of homosexual sex. That study and its findings were described in a New York Times article by Pam Bullock, "Many Genes Influence Same-Sex Sexuality, Not a Single 'Gay Gene"' (Bullock, 2019). Also there was an accompanying article, "What Genetics Is Teaching Us About Sexuality", by two researchers one of whom was involved with the research project (Phelps \& Wedow, 2019). Those researchers were biologist Steven M. Phelps of the University of Texas at Austin, and a project researcher, sociologist and geneticist Robbee Wedow of M.I.T and Harvard. Both men happen to be gay.

It had been a carefully done study and as Bullock's article pointed out, "[e]xperts widely agree that the research was conducted by first-rate scientists". The researchers not only plunged into the requisite scientific (mostly statistical) analyses, they also apparently labored intensively to put together a sensitive presentation of their findings. Additionally mentioned was that trans individuals were excluded from the study. The investigation was essentially billed as a success. It seemed rather ambiguous, though, and this was succinctly captured in the Readers Picks comments for the Phelps and Wedow article. One of these read:

[t]his research clearly shows that there is no straight answer-pun unintended. If looking into the DNA of 500,000 people didn't help, what will?

Another reader got a bit animated:

[1]ess than $1 \%$ of variation!

I almost choked on my pork and beans when I read that.

Less than $1 \%$ of variation is risible, not even the beginnings of understanding the phenomenon.

Dudes, get back to us if and when you have something to report.

I appreciated the frankness of these comments but must now let the findings as given in Bullock's article speak for themselves. After some generalities the article reported that:

[r]esearchers specifically identified five genetic variants present in people's genomes that appear to be involved. Those five comprise less that 1 percent of the [inferred] genetic influences, they said.

And when the scientists tried to use genetic markers to predict how people in unrelated data sets reported their sexual behavior, it turned out to be too little genetic information to allow prediction.

In fact, the above comments accurately pointed out that they really didn't find anything.

For further context, though, the "Dudes" commenter also asserted a mocking "[h]ello, all behavior is influenced by DNA". But are there any behavioral genetic studies that have credibly identified DNA origins? In fact in a 2014 review article of another "breakthrough" with regards to the genetics of intelligence (which purported to account for a possible 1 percent of the variation in our innate intel- 
ligence), Scientific American's John Horgan reflected back to a 2012 Behavioral Genetics editorial that had stated:

[t]he literature on candidate gene associations is full of reports that have not stood up to rigorous replication. This is the case both for straightforward main effects and for candidate gene-by-environment interactions...As a result the psychiatric and behavioral genetics literature has become confusing and it now seems likely that many of the published findings of the last decade are wrong or misleading and have not contributed to real advances in knowledge (Horgan, 2014).

This was another under-appreciated important story.

In summary very large efforts have been made to identify the genetic origins of a range of human characteristics. Officially the outcomes of such searches have often been characterized as a bit less successful than expected. Such assessments appear to have been inaccurate.

\section{Basic Challenges to DNA's Role}

There are existing simple problems, though, facing the inheritance vision. Two gross ones are the inexplicable differences present between monozygotic twins and also the existence of some truly remarkable behaviors. I will first briefly describe some monozygotic puzzles. The cause of their origin-the initial split or division of a single cell zygote-is a mystery. So is its occurrence only in some species. Further, similar appearances and biological-presumptions aside, identical twins in fact constitute obvious challenges to the sacred DNA logic of "created [us], body and mind" (Dawkins, 1976: p. 20). Although they share a DNA blueprint, such twins whether they were raised together or separately, have been observed on average to be a bit more different than alike in terms of their personalities (Pinker, 2002; Harris, 2006). Thus these genetic clones can closely share the same environment or inhabit separate ones and they still appear to have markedly different personalities. Furthermore, in the large Minnesota Study of twins raised separately a key conclusion was that "[o]n multiple measures of personality and temperament, occupational and leisure-time interests, and social attitudes, monozygotic twins reared apart are about as similar as are monozygotic twins reared together" (Bouchard et al., 1990).

Thus it is not clear what environmental basis is available for the epigenome (or other mechanisms) to differentiate twins. If the differences between twin pairs are largely insensitive to being raised separately, then that doesn't appear to leave much of a window for significant environmental differentiation and thus Pinker acknowledged that "something is happening here but we don't know what it is" (Pinker, 2002: p. 380).

In Judith Rich Harris' No Two Alike she pointed out that even conjoined (or attached) twins appear to be markedly different. As one such twin reported (prior to an unsuccessful separation surgery), "[w]e are two completely separate individuals who are stuck to each other. We have different world views, we have 
different lifestyles, we think very differently about issues" (Harris, 2006: p. 1). This mystery seems to have generated some puzzlement within psychology (see for example discussions in Pinker's The Blank Slate), but it does not seem to have much general recognition. One succinct example of the surprising individuality of monozygotic twins is with regards to male exclusive homosexuality where there is only about a 20 to 30 percent concurrence rate among (male) monozygotic twins (Collins, 2010: pp. 204-205). There are also large differences between monozygotic disease histories, and only slight decreases in the variance of their longevities versus fraternal twins (Kolata, 2006).

Continuing, prodigies can exhibit stunning abilities and drives (Solomon, 2012; Treffert, 2010) and Daryl Treffert acknowledged that some prodigies even appear to exhibit knowledge of things they never learned. One example in Treffert's Islands of Genius (Treffert, 2010) was a musical prodigy:

By age five Jay had composed five symphonies. His fifth symphony, which was 190 pages and 1328 bars in length was professionally recorded by the London Symphony Orchestra for Sony Records. On a 60 Minutes program in 2006 Jay's parents stated that Jay began to draw little cellos on paper at age two. Neither parent was particularly musically inclined, and there were never any musical instruments, including a cello, in the home. At age three Jay asked if he could have a cello of his own. The parents took him to a music store and to their astonishment Jay picked up a miniature cello and began to play it. He had never seen a real cello before that day. After that he began to draw miniature cellos and placed them on music lines. That was the beginning of his composing.

Jay says that the music just streams into his head at lightning speed, sometimes several symphonies running simultaneously. "My unconscious directs my conscious mind at a mile a minute," he told the correspondent (Treffert, 2010: pp. 55-56).

For context here as the late prominent biologist Ernst Mayr pointed out that, " $[t]$ he entire behavioral information available to the newborn is contained in its DNA" (Mayr, 2001: p. 253). Is this plausible in the case of prodigies? Prodigies deserve considerably more attention (in an intellectual, not personally-intrusive, fashion).

In the case of transgender kids they exhibit surprising cross-gender orientations. Thus little biological boys can make claims like that when they grow up they will "adopt my babies, but I'll have boobies to feed then and I'll wear a bra, dresses, skirts, and high-heeled shoes" (Solomon, 2012: pp. 605-606), and furthermore after thoroughly testing such kids researchers can state that:

[a]ll of this research combines to show that transgender identities in even very young children are surprisingly solid and consistent across measures, contradicting popular beliefs that such feelings are fleeting or that children are simply pretending to be the opposite gender (Olson, 2017). 
Scientifically, such inclinations should be encoded in DNA and also somehow consistent with fallout from evolution.

Moving along here to consider a final behavioral challenge to genetic logic, the extensive memory syndrome, hyperthymesia. This syndrome involves extensive autobiographical recall and was considered in a Scientific American article, "Remembrance of All Things Past" (McGaugh \& Leport, 2014). That article opened with an excerpt from an e-mail that the author/researcher James McGaugh had received from a woman named Jill Price:

As I sit here trying to figure out where to begin explaining why I am writing you...I just hope somehow you can help me. I am 34 years old, and since I was 11 I have had this unbelievable ability to recall my past...I can take a date, between 197[6] and today, and tell you what day it falls on, what I was doing that day, and if anything of great importance...occurred on that day I can describe that to you as well.

The authors, McGaugh and LePort, then extensively tested Price's recall. Her memory was eventually proved faulty in only one case-the day of the week of one of the previous 23 Easters (and Price is Jewish). During testing she "corrected the book of milestones for the date of the start of the Iran hostage crisis at the U.S. embassy in 1979". Also during the tests she:

correctly recalled that Bing Crosby died at a golf course in Spain on October 14,1977 . When asked how she knew, she replied that when she was 11 years old, she heard the announcement of Crosby's death over the car radio when her mother was driving her to a soccer game.

Price appeared to demonstrate an "immediate recall of the day of the week for any date in her life after she was about 11 years old". It is interesting to note that she also "has trouble remembering which of her keys go into which lock" and moreover "does not excel in memorizing facts by rote". The remainder of McGaugh and LePort's article included mention of their subsequent confirmation of hyperthymesia in about 50 people. Such memories were found to be "highly organized in that they are associated with a particular day and date" and they also occurred "naturally and without exertion".

That this capacity is untrained and effortless strongly suggests that it is innate and as such an expression of DNA. The authors acknowledged this point. That would mean that such people should have a specific DNA pattern that somehow fell out of our evolutionary history that allows them to effortlessly recall their lives and significant events, in a date and day-of-the-week fashion (the latter seemingly entailing a modulo 7 dating orientation). I suggest that this is a good introduction to some of the extraordinary expectations placed on DNA (and also brains).

\section{Considering Evolutionary Challenges}

Ernst Mayr's What Evolution Is captured some of the potential evolutionary sig- 
nificance of the unfolding missing heritability with regards to behaviors. In it Mayr wrote:

[ $\mathrm{t}$ ] here are reasons to believe that behavioral shifts have been involved in most evolutionary innovations, hence the saying "behavior is the pacemaker of evolution." Any behavior that turns out to be of evolutionary significance is likely to be reinforced by the selection of genetic determinants for such behavior (known as the Baldwin effect). (Mayr, 2001: p. 137).

Thus, innate behaviors should have DNA origins and moreover such genetic components likely had resonances with natural selection and could have had significant evolutionary impacts. Some speciations (or species-creating) events are believed to have been driven by behavioral differentiation. In fact among the Hawaiian genus of crickets, Laupala, there appear to be 38 separate species and the distinguishing aspect amongst them is the males' mating song along with the corresponding females' song preference (Herron \& Freeman, 2014: pp. 625-626). Those songs consists of very simple series of pulses and the distinguishing song feature appears to be the pulse rate. Somehow the collection of Laupala crickets in Hawaii appear to have binned or segregated themselves off on the basis of males' mating call frequencies! Additionally of note here is that this behavioral dynamic has "astonishing[ly]" evaded efforts to isolate its genetic basis.

Given the unfolding failure to identify the DNA origins for a number of human behavioral tendencies this suggests that DNA is deficient in its "language of life" role. An analogous situation has unfolded for many disease susceptibilities. At the same time, though, there are well established DNA origins, in particular for a number of particular disorders and physical features. In addition to some relatively common conditions such as sickle cell anemia, there are as James D. Watson et al. pointed out "vast numbers of single-gene disorders-the current genetic disease database lists several thousand-but the majority are extremely rare, each occurring in just a few families" (Watson, 2017: p. 337). So the current confirmed DNA-heritability situation might be outlined as sporadic successes set against some unfolding broad failures in the realms of behavior and health tendencies. You might also infer a genetic basis for the overall layout of bodies since monozygotic twins often have very similar appearances. This suggests that either the heritability failures reflect flaws in genetic analyses, or that those failures accurately characterize the limited functioning of DNA.

Finally, before exploring evolutionary challenges there are some basic observations about DNA worthy of additional consideration. It turns out that evolutionary dynamics appear to have modified DNA in a haphazard fashion. This is apparent in the enormous variability in the size of genomes amongst different organisms (Herron \& Freeman, 2014: pp. 582-591). For example, an onion or a broad-footed salamander have genomes five and fifty times larger than our own, respectively. Also estimates of the functional portion of our own genomes are quite low-only 8 percent in one estimate (Zimmer, 2015). Furthermore, there is 
substantial ambiguity apparent in the workings of DNA. This is apparent in the divergence of monozygotic twins (bolstered by the apparent limits of environmental influence), and also in the variability of symptoms expressed by bearers of some disease-specific alleles. That variability is sometimes termed penetrance or variable expressivity. These two phenomena-the haphazardness and the ambiguity associated with DNA-seem to be at odds with the kind of precision required for a number of DNA's roles.

\subsection{Primate Color Vision}

A simple example of an evolutionary dynamic is considered. In a fine Scientific American article, "The Evolution of Primate Color Vision", by Gerald H. Jacobs and Jeremy Nathans the apparent historical development of the trichromacy in old world primates is described (Jacobs \& Nathan, 2009). Instead of the common two distinct visual pigments, the eyes of old world primates (including humans) have three, facilitating improved color vision. The underlying transformation apparently involved a sequence of errors in DNA processing by which the earlier (mammalian) two pigment genes were changed into three (apparently involving some mutations followed by a recombination error). That updated DNA, as demonstrated in some impressive experiments with mice, likely allowed for better distinguishing of the color spectrum. For reasons including the possible improvements in the ability to distinguish ripe fruit, this genetic update was a natural selection winner and thus spread over time.

What is significant here is that the requisite physics is not complicated. Some changes in a stretch of the DNA molecule produced an additional blueprint for a pigment which in turn could be utilized in retinas to significant effect. The resulting improved optical response came directly from the new pigment which in turn came directly from the new gene. This historical dynamic certainly appears to be plausible. Behavioral updates on the other hand, would seem to require much more complicated DNA updates to ultimately elicit coherent changes in brain function.

\subsection{Wasps versus Cockroaches and Other Instinctive Behaviors}

On the other hand, are highly detailed innate or instinctive behavioral routines really feasible in organisms beginning with the underlying DNA specifications? The text Evolutionary Analysis has a number of examples but I turned to another source for a recent update on an instinctive behavior.

The example considered here comes from an excellent Scientific American article, "Attack of the Zombie Maker", by Kenneth C. Catania (Catania, 2021). The article chronicles Professor Catania's investigation into the amazing reproductive behaviors of emerald jewel wasps. These wasps carry out remarkable (and brutal) takeovers of the bodies of American cockroaches in order to facilitate the feeding and development of their larva. In investigating the remarkable attacks of these wasps Catania inadvertently observed and then studied an additional phenomenon. The resulting process, like the also elaborate defensive response he 
observed on the part of some American cockroaches, is believed to be an unlearned routine and as such an expression of elaborate genetic programming.

Catania begins his article with a quotation from the 1979 classic horror movie, Alien. That quote offered an admiring interpretation by an android on the performance of that movie's evil creature. The quote was:

You still don't understand what you're dealing with, do you? Perfect organism. Its structural perfection is matched only by its hostility... I admire its purity. A survivor, unclouded by conscience, remorse or delusions of morality.

That movie's alien took over a human body in order to provide for the development of its young. The analogous emerald jewel wasp takeover of the body of a cockroach provides the necessary circumstances for the wasp's offspring. By doing this the jewel wasp is officially classified as a parasitoid.

Catania introduces his subject by reviewing what had previously been uncovered about the emerald jewel wasp's attack on the American cockroach. That attack begins by:

paralyzing its host, first stinging the cockroach directly in a part of the central nervous system called the first thoracic ganglion. This structure houses the motor neurons that control the roach's front legs. The wasp's venom contains gamma-aminobutyric acid (GABA), an inhibitory neurotransmitter that shuts down the motor neurons, temporarily paralyzing the legs. This first surgical strike leaves the roach unable to protect its head from the next sting, which the wasp directs through the soft membranes of the roach's throat and straight into its brain. The second dose of venom has the insidious effect of changing the roach from a violently struggling (and dangerous) opponent into a compliant and pacified host-that is, a zombie. From there things go predictably downhill for the roach

That second sting's venom includes the neurotransmitter dopamine which specifically appears to cause the roach to focus on grooming itself instead of trying to escape.

The jewel wasp next goes and searches for a place to permanently store the disabled cockroach. When the wasp returns to the incapacitated roach it "grasps one of the roach's sensitive antenna and bites off most of its length" and then repeats the process on the other antenna. The resulting bleeding antennae stumps then effectively provide straws for the wasp to replenish itself by drinking the victim's blood. The wasp then drags its prey by one of the antenna stumps into the located tomb and further glues a single egg onto one of the roach's legs. Finally, the wasp seals the tomb.

Professor Catania then went on summarize this remarkably brutal takeover routine with:

Take a moment to consider this astounding product of evolution. For any predator, it is plenty hard to stalk, catch and kill elusive prey. The emerald 
jewel wasp has an even greater challenge-taking its prey prisoner so it can serve as a living larder for the larva when it eventually hatches. To do so, the jewel wasp must deliver venom to two small neural targets inside the armored body of an insect that specializes in escaping from threats.

This implies incredible shaping of innate behavior via natural selection acting on DNA. I suggest here that no one really understands how this could happen.

As Catania found out there is even more to the jewel wasp's takeover routine. It turns out that the two sting routine is not sufficient for the fruitful placement of the wasp's egg. After hatching, the resulting larva is rather feeble and thus often unable to find a viable opening into the cockroach's body. The mother wasp, thus, has to further manipulate the cockroach in order to glue the egg in a spot where the larva can subsequently penetrate the roach's armor. This entails the wasp stinging a third time, this time in the roach's second thoracic ganglion. This particular sting (and associated venom) causes the roach to extend one of its middle legs. That in turn exposes what seems to be the prime location for the wasp to precisely glue its egg.

A further layer of the wasp-versus-cockroach conflict was also uncovered. Catania noticed that in some cases an American cockroach will assume an effective defensive position by standing tall on its legs (deemed the "stilt-standing posture") whereby it can square up to the attacking jewel wasp. One defending action was noted as particularly effective-using its long legs to sidekick the wasp in the head. Such kicks had a big impact knocking the wasp "through the air until it crashed into the nearest object" and after taking a few such kicks the wasp would usually call off the attack.

All of these actions by these insects are presumed to be unlearned behaviors or instincts. There is no evidence that the wasps are taught their very elaborate attack procedure or that some of the cockroaches learn their defensive routine (as though they had attended some form of self-defense classes).

I consider further here the emerald wasp's attack routine. Note the third level of the attack involving the final sting and strategic placement of the larva. Perhaps this third level evolved in response to some kind of defensive development on the part of American cockroaches. The third level then in accordance with evolution's logic would have taken shape in the form of selecting out variable DNA (alleles) in such a way as to accurately apply the third sting and then also subsequently place the larva. Notice that this natural selection development would also face significant constraints in that those selected variants should not interfere with existing vital functions of the emerald jewel wasp, including those specifying the first two levels of the egg-laying attack. Even skimping on some details here-as Catania observed the jewel wasp also somehow utilizes its own abdominal hair as a means to place the larva-this seems unlikely.

Additional amazing instincts of note exists as well. Some birds have been shown to demonstrate an innate knowledge of their migration routes, a point on which even the Nobel laureate James D. Watson expressed astonishment (Wat- 
son, 2003). Also a number of animals-including dung beetles-appear to utilize the positions of nighttime stars in order to navigate (Sokol, 2021)! From a scientific perspective does it really appear possible that a molecule-deoxyribonucleic acid (DNA) - could be shaped by natural selection to encode for the making of a brain so precisely enhanced for navigation?

\subsection{Kin Selection}

Next, consider some basic phenomena presumed to be shaped by kin selection. This is described as when natural selection favors "traits that result in decreased direct fitness if they increase the survival and reproductive success of close relatives" (Herron and Freeman, 2014: p. 460). These traits in effect can work to the detriment of an individual bearer thereof, but in turn can help further the underlying responsible genetic allele's frequency. This can happen since the bearer's relatives are more likely to also have that specific genetic allele (and thus trait). In this somewhat roundabout fashion, natural selection appears to be able to support the behavioral bias of favoring one's own relatives.

This phenomenon had challenged Charles Darwin's thinking as on the face of it an "allele that results in behavior benefiting other individuals at the expense of the allele bearer would seem destined for elimination by natural selection" (Herron \& Freeman, 2014: p. 459). Darwin's intuition here was eventually formalized in the form of dual versions of fitness, direct and indirect fitness. The direct fitness of a trait/gene is a measure of its contribution to an individual's reproductive success, while indirect fitness is a measure of its contribution to that of relatives. A simple example might be a particular DNA variation (or allele) that somehow furthers maternal care inclinations. The resulting boost in maternal tendencies might come at a cost to mothers bearing the allele, but that boost could well increase the likelihood of the survival of their offspring and subsequent reproductive successes (and in this way furthering the frequency of the associated motherhood allele).

Continuing here with some kin selection examples from the Herron and Freeman text, Evolutionary Dynamics. One example involved the tendency of blacktailed prairie dogs to give warning barks when they observe a predator (Herron \& Freeman, 2014: p. 462). Such warning barks would seem to entail putting the voicing dog at additional risk. In watching the prairie dogs the researchers observed a roughly twofold increase in alarm production for those dogs living in a den with genetic kin, versus those without kin. The researchers felt that they had observed "nepotistic" behavior which should "result in indirect fitness gains".

Another kin selection study looked at the adoption of orphaned, nursing baby squirrels by mother squirrels (Herron \& Freeman, 2014: p. 463). The researchers found that among 34 litters orphaned during lactation, 7 were concurrent with available lactating squirrel moms who also happened to be genetic relatives. In five of these circumstances a squirrel kitten was adopted by a relative mom. With the other 27 litters there were no available lactating related moms and 
none of the squirrel kittens in those litters was adopted. Somehow the squirrel mothers appeared to factor in a genetic connection with their decisions on whether to adopt.

In another study, some researchers observed the chick-care efforts of reed buntings (a small ground-nesting bird) (Herron \& Freeman, 2014: pp. 586-570). Reed buntings turn out to be monogamous socially, but not otherwise. Consequently, one set of genetic tests found that $86 \%$ of the nests contained chicks that were sired by a male other than the nest (and social) mate of the mother bird. Researchers wanted to observe the parental care of the mothers and fathers relative to the fraction of chicks sired by an outsider. They thus considered the relative feedings provided by mothers and fathers across two clutches or broods in a single season. Consistent with the logic of kin selection, the researchers noted that fathers tended to provide more feedings to nest mates in nests with a higher percentage of chicks they had sired. For mothers, though, there wasn't a corresponding statistically significant difference in their treatment of the two broods. In commenting on this finding, Herron and Freeman, suggested out that the male "bird's brain has a mechanism that adjusts the level of effort the male expends in caring for a brood, based on cues that indicate his probable level of paternity" in the brood. This is a remarkable ability.

A human study examined 1000 wills written in British Columbia and the associated breakdown of the planned wealth redistribution. The study found that $55.3 \%$ of that wealth was bequeathed to kin versus only $7.7 \%$ to non-kin. The remaining $37 \%$ was bequeathed to spouses. The researchers then further looked at the breakdown of the planned distribution to kin to see if closer relatives (offspring and siblings) were to receive more than those further removed (grandkids, nieces, nephews, and cousins). The closer relatives in fact were designated to receive $46.5 \%$ of the wealth versus only $8.9 \%$ for those further akin. Although, this scenario certainly could be influenced by cultural factors, Herron and Freeman reported that the researchers:

Concluded that the data are in broad accord with kin selection theory. This does not require us to imagine that people composing wills routinely draw pedigrees, calculate direct [fitness] costs and indirect [fitness] benefits, and divide the wealth accordingly. It suggests only that natural selection among our ancestors left us with a tendency to feel more generous to more closely related kin (Herron \& Freeman, 2014: p. 464).

The above conclusion that kin selection "suggests only that the natural history of our ancestors has left us tending to feel more generous to close kin" is understated. That the survival and reproductive historical record somehow established DNA alleles to allow for individual organisms to have been apparently built with brains that can detect and then preferentially treat others based on possible genetic ties is amazing. Think of the above case involving mother squirrels. Somehow the squirrel moms can apparently distinguish kin versus non-kin orphaned baby squirrels and then tend to treat them differently. On the hand, it 
took an extended intellectual effort across 9 years involving the efforts of researchers to tag individual squirrels and then monitored their survival and reproductive successes. All told the researchers had observed and recorded the significant outcomes of 2230 litters from 1101 squirrel moms. Is it really reasonable to assume that natural selection-beget DNA specifics have equipped individual squirrel moms to behave in agreement with kin selection?

Additionally there have been a number of observations suggesting that children raised by two biological parents have it better than those raised by one or more non-biological parents (the examples considered in Herron and Freeman the non-biological parent appeared to be limited to fathers). Studies cited were based on observations of premodern cultures which found that fathers appear to treat their biological children better than their stepchildren, and also that the former are more likely to survive childhood ( $81 \%$ versus $57 \%$ percent for a group of Indians in Paraguay) (Herron \& Freeman, 2014: p. 572).

Another study considered children raised in a rural Caribbean (Dominca) village under these two scenarios (Herron \& Freeman, 2014: pp. 572-573). This study found that those living with two biological parents tended to have lower cortisol levels which implies lower stress levels. The children who grew up with a co-resident stepdad also tended to experience more illness (which is correlated with higher cortisol levels) and it was reported that the additional burden of sickness appeared to exceed what was expected from socioeconomic factors.

A final study considered the relative outcomes for the two groups of children with regards to a terrible outcome, that of being a homicide victim of a parent. This was a thankfully rare event, but it was considered a significant test of evolutionary logic and the data base consisted of records from all of Canada during the period from 1974 to 1983 . It turns out that such homicides tend to occur more often with young children. The total number of homicides counts were 341 and 67 for children raised without and with a co-resident stepparent, respectively. For meaningful consideration these numbers were converted into rates and given the relative rarity of young kids raised with a resident stepparent (only 0.4\% of Canadian one to four year olds in 1984 lived with a stepparent) those differences turned out to be sizable. From Herron and Freeman the resulting synopsis:

For children zero to two years old, the relative risk of parental homicide for stepchildren versus biological children is about 70 . This is an extraordinarily high relative risk. For comparison, the relative risk of lung cancer in smokers versus nonsmokers is about 11 (Herron \& Freeman, 2014: p. 574).

This very significant and sad phenomenon is once again attributed to a natural selection-beget capacity to differentiate between kin and non-kin and to then favor kin. Again, though, as emphasized in Herron and Freeman, these thankfully appear to be rare occurrences of excessive response.

An additional point and possible challenge here is that any explanation for our tendency to be biased towards kin also has to allow for some contradictory 
behaviors. Killing amongst siblings (siblicide) is common in nature and that challenges evolutionary logic (Herron \& Freeman, 2014: p. 480). In particular, killing a sibling who shares about half of their variable DNA with you challenges the logic of kin selection (whereby genes are posited to have been selected to tend to preserve themselves across generations).

Such kin-based behavioral biases appear to be pervasive and from a scientific perspective have to have genetic origins. DNA is supposed to provide "[ $t$ ]he entire behavioral information available to the newborn" (Mayr, 2001: p. 253). But such a relationship for kin biases is not easy to imagine.

\subsection{Our Innate Religious Perspectives}

Although not covered in the evolutionary literature that I am aware of, we appear to come equipped with our own natural religious beliefs or inclinations. In the book, Born Believers - The Science of Children's Religious Belief, the author Justin L. Barrett laid out some of the evidence that infants tend to have an innate belief in the existence of souls/God/gods, to be believers in what Barrett terms a "natural religion" (Barrett, 2012). The book contained a number of striking examples including ones in which the positions of atheists' were rebutted by their young children. As Barrett wrote " $[c]$ hildren are prone to believe in supernatural beings such as spirits, ghosts, angels, devils, and gods during the first four years of life" (Barrett, 2012: p. 3). He later added:

Exactly why believing in souls or spirits that survive death is so natural for children (and adults) is an area of active research and debate. A consensus has emerged that children are born believers in some kind of afterlife, but not why this is so (Barrett, 2012: p. 120).

Barrett included a chapter listing some basic details associated with our natural religion. These details had been obtained from research into children's beliefs and they suggest that humans are born inclined to hold several beliefs including:

1) That there are "[s] uperhuman beings with thoughts, wants, perspectives, and emotions."

2) That "[e]lements of the natural world such as rocks, trees, mountains, and animals are purposefully and intentionally designed by some kind of superhuman being(s), who must therefore have superhuman power."

3) That "[s]uperhuman beings generally know things that humans do not (they can be super-knowing or super-perceiving, or both), perhaps particularly things that are important for human relations."

4) That "[s]uperhuman beings may be invisible and immortal, but they are not outside space and time". They also "have character, good, or bad."

5) That "[1]ike humans, superhuman beings have free will and can and do interact with people, sometimes rewarding and sometimes punishing them."

6) That "[m]oral norms are unchangeable, even by superhumans."

7) That "[p]eople may continue to exist without their earthly bodies after death.” (Barrett, 2012: pp. 138-39) 
In summation, children seem to be inclined to believe that there is an unseen and significant other living realm, which has an overlapping presence including a design-oriented one.

Barrett went on to carefully and rather extensively qualify findings about our natural religion. In particular he emphasized that these beliefs are conceptually primitive and that their extension into agreement with more typical religious theology is not easy. It appears that young children (and Barrett suggested adults too) might be naturally religious, but on the other hand they're not theologically inclined.

These remarkable findings were simply placed within a scientific framework, as some kind of fallout from evolution and nurture-or "biology plus ordinary environment". Barrett, in fact, went so far as to suggest that research into "systems of the human mind" "make belief in some kind of god almost inevitable" (Barrett, 2012: p. 20). Let me suggest that that statement (and Barrett's subsequent followup, as well as T. M. Luhrmann's (2020) How God Becomes Real) is an excellent example of the hegemony of scientific materialism, since it is extremely difficult to imagine concluding that innate religious beliefs are biologically "almost inevitable".

Barrett and other researchers apparently have found some satisfaction, though, in rebutting the common anti-religious argument that with regards to the origins of religious beliefs, people simply parrot what they've been taught. Barrett did offer an alternative explanation that he heard from an Indian man. In Barrett's words that man had explained:

[T] hat on death, we go to be with God and are later reincarnated. As children had been with God more recently, they could understand God better than adults can. They had not yet forgotten or grown confused and distracted by the world. In a real sense, he explained, children came into this world knowing God more purely and accurately than adults do (Barrett, 2012: p. 2).

I add here a couple of relevant examples from my own experience. One involved having a child of about 3 years old walk into an adult conversation I was in and simply say, "There is a God". The child then paused and repeated this. I remember that the adult conversation I was involved with had touched on the subject of God and could well have involved a questioning of God's existence. As far as I know that 3 year old had no supporting religious background and even if he did I doubt it would have mattered. It was striking to have an obviously sincere child insist on the existence of God with a conviction seemingly on par with a declaration of "I need to go to the bathroom".

In a second incident a child who was about 5 or 6 years matter of factly said to me, "And when we die we go around and find a new mother and go in her tummy and then get born, isn't that right?". I do know that this child was part of a Muslim family that didn't teach reincarnation. Along with the first case these standout as sincere, out-of-the-blue comments by children that seem consistent 
with our purported natural religion.

\section{Conclusion}

The modern understanding of life is based on what appear to be fantastic assumptions about the workings of DNA. The excessive nature of those assumptions should be increasingly clear in the wake of the search failures encountered following up the Human Genome Project. If readers are curious about possible loopholes in the scientific vision of life-including evolution-let me suggest that this hole is conceptually big enough to allow a Boeing 747 to fly through it.

Briefly I touch on two possible alternative explanatory frameworks. The biologist Rupert Sheldrake has argued that the expectations for DNA's functioning should have been seen as excessive all along. He does so by noting the enormous complexity inherent in the specifications required for the functional shaping of proteins; further along in the structuring of cells; and onto instincts (Sheldrake, $2012 a, 2012 b)$. His approach picks up on the historical work which suggested the need for morphogenetic or memory-based guiding fields in order to help realize organisms' complicated functional forms and also their behaviors (Sheldrake even goes further with a number of parallel hypotheses for physics). According to this model, DNA's role is limited to specifying blueprints for an organism's proteins, and beyond this, the model suggests that the complicated development of organisms relies on the memory of earlier organisms' development. For a simple example consider that the stunning un-learned ability of some birds to know their migration routes could then reflect their utilization of memory fields established by earlier migratory efforts. See Sheldrake's works for a thorough presentation. Additionally of note, is that after exiting the scientific establishment Sheldrake has continued to do a wide variety of investigations and seemingly maintained polite composure amidst being predictably attacked for his heresy.

Another possible alternative heritability explanation is with the premodern sequential-life or reincarnation paradigm. You can see the beginnings of this suggested in the realm of investigations into possible cases of reincarnation (Stevenson, 1997, 2000; Tucker, 2005). At the end of his Where Reincarnation and Biology Intersect, Ian Stevenson suggested that, [w]e may, after all, be engaged in a dual evolution-of our bodies and of our minds or souls" (Stevenson, 1997: p. 187). A basic further point, though, is that such a dual evolution would very likely have to been a joint process as happenstance-only appears very unlikely to have beget homo sapiens (Christopher, 2020).

A life-after-life explanation would place the memory-based contributions on the incarnating souls. This approach could provide explanations for such puzzling phenomena as prodigies and transgender children. It might also provide explanations for the enormous variance found in the personalities of animals (Angier, 2010). Another simple explanation could be with regards to peculiar innate phobias (Stevenson, 1997, 2000), and also perhaps with instinctive phobias. In general, an underlying dynamic of souls' being drawn to their parents-to- 
be (as traditionally believed), along with a tendency to maintain behavioral inclinations, allows for a gross fit to the missing heritability problem for behavioral tendencies, and more subtly perhaps with disease tendencies (Christopher, 2017a, 2017b). That same draw-to-parents dynamic might also provide a basis for kin bias. In a simple behavioral example, a number of problematic behaviors like excessive drinking of alcohol and also smoking appear to be heritable (such that "more than 50 percent of the overall risk for alcoholism is attributable" to genetic factors) (Nurenburger \& Bierut, 2007). But instead of expecting a questionable DNA/physical basis for problematic habits, the transcendental alternative is to view the habit as an expression of behavioral continuity. A soul previously got stuck in an unhealthy habit and eventually was drawn in their rebirth towards previously connected people (as parents-to-be, who might well share their habit), and unfortunately that challenge tends to continue in their subsequent life. See Christopher's work for an introduction to reincarnation's possible general role.

Questioning the scientific understanding of life appears to be overdue. I am not aware of academics looking into this critical topic, and this surprisingly appears to include people in the fields of philosophy and religion. Elsewhere I have also sensed little interest as perhaps many assume the scientific position has already been confirmed. Hopefully, the unfolding crisis in genetics will spur more people to consider alternatives or simply novel contributions. From the very strong information encoding demands of some instinctive behaviors; to some remarkable human innate syndromes; to the marked behavioral discordance observed between monozygotic twins-questions with regards to the completeness of the scientific vision, beginning with DNA's language of life role, seem appropriate now.

\section{Acknowledgements}

The author gratefully acknowledges the Central Library of Rochester and Monroe County. Several significant books were obtained there and the library also provided a good work space. The efforts and funding came solely from the author.

\section{Conflicts of Interest}

The author declares no conflicts of interest.

\section{References}

Allegrini, A. G., Selzam, S., Rimfeld, K., von Stumm, S., Pingault, J. B., \& Plomin, R. (2019). Genomic Prediction of Cognitive Traits in Childhood and Adolescence. Molecular Psychiatry, 24, 819-827. https://doi.org/10.1038/s41380-019-0394-4 https://www.biorxiv.org/content/10.1101/418210v1

Angier, N. (2010). Even among Animals: Leaders, Followers, and Schmoozers. New York Times.

Balter, M. (2017). Schizophrenia’s Unyielding Mysteries. Scientific American. 
Barrett, J. L. (2012). Born Believers-The Science of Children's Religious Belief. New York: Free Press.

Berg, J. J., Harpak, A., Sinnott-Armstrong, N., Joergensen, A. M., Mostafavi, H., Field, Y., Boyle, E. A., Zhang, X., Racimo, F., Pritchard, J. K., \& Coop, G. (2019). Reduced Signal for Polygenic Adaptation of Height in UK Biobank. eLife. https://doi.org/10.7554/eLife.39725

Bouchard, T. J., Lykken, D. T., McGue, M., Segal, N. L., \& Tellegen, A. (1990). Sources of Human Psychological Differences: The Minnesota Study of Twins Reared Apart. Science, 250, 223-228. https://doi.org/10.1126/science.2218526 http://web.missouri.edu/ segerti/1000H/Bouchard.pdf

Bullock, P. (2019). Many Genes Influence Same-Sex Sexuality, Not a Single 'Gay Gene’. New York Times.

Catania, K. C. (2021). Attack of the Zombie Maker. Scientific American.

Cepelewicz, J. (2019). New Turmoil over Predicting the Effects of Genes. Quanta Magazine: Genomics.

https://www.quantamagazine.org/new-turmoil-over-predicting-the-effects-of-genes-20 $\underline{190423 /}$

Christopher, T. (2017a). Science's Big Problem, Reincarnation's Big Potential, and Buddhists' Profound Embarrassment. Religions, 8, Article No. 155.

http://www.mdpi.com/2077-1444/8/8/155

https://doi.org/10.3390/rel8080155

Christopher, T. (2017b). A Hole in Science: An Opening for an Alternative Understanding of Life (3rd ed.). Self-Published.

Christopher, T. (2020). Religion versus Science II: Why Science Is Wrong About Life and Evolution, and Where Religious Beliefs Can Find Objective Traction. Religions, 11, Article No. 495. https://www.mdpi.com/2077-1444/11/10/495

https://doi.org/10.3390/rel11100495

Collins, F. (2010). The Language of Life: DNA and the Revolution in Personalized Medicine. New York, NY: Harper Collins.

Dawkins, R. (1976). The Selfish Gene. New York: Oxford University Press.

Green, E. D. (2013). Human Genome, Then and Now. New York Times.

Hall, S. S. (2010). Revolution Postponed: Why the Human Genome Project Has Been Disappointing. Scientific American.

Harris, J. R. (2006). No Two Alike. New York: W. W. Norton \& Company.

Herron, J. C., \& Freeman, S. (2014). Evolutionary Analysis (5th ed.). Pearson Education.

Horgan, J. (2014). Quest for Intelligence Genes Churns Out More Dubious Results. Scientific American.

https://blogs.scientificamerican.com/cross-check/2014/10/14/quest-for-intelligence-ge nes-churns-out-more-dubious-results/

Jacobs, G. H., \& Nathans, J. (2009). The Evolution of Primate Color Vision. Scientific American.

Kingsley, D. M. (2009). From Atoms to Traits. Scientific American.

Kolata, G. (2006). Live Long? Die Young? Answer Isn't Just in Genes. New York Times.

Latham, J., \& Wilson, A. (2010). The Great DNA Data Deficit: Are Genes for Disease a Mirage? Independent Science News.

https://www.independentsciencenews.org/health/the-great-dna-data-deficit/

Lee, J. J. et al. (2018). Gene Discovery and Polygenic Prediction from a 1.1 Million-Person 
GWAS of Educational Attainment. Nature Genetics, 50, 1112-1121.

https://scholar.harvard.edu/files/laibson/files/ssgac nature-genetics 072318.pdf https://doi.org/10.1038/s41588-018-0147-3

Lello, L., Avery, S. G., Tellier, L., Vazquez, A. I., de los Campos, G., \& Hsu, S. D. H. (2018). Accurate Genomic Prediction of Human Height. Genetics, 210, 477-497.

https://www.genetics.org/content/210/2/477 https://doi.org/10.1534/genetics.118.301267

Luhrmann, T. M. (2020). How God Becomes Real. Princeton, NJ: Princeton University Press.

Mayr, E. (2001). What Evolution Is. New York: Basic Books.

McGaugh, J. L., \& LePort, A. (2014) Remembrance of All Things Past. Scientific American.

Nurenburger, J. I., \& Bierut, L. J. (2007). Seeking the Connections: Alcoholism and Our Genes. Scientific American.

Olson, K. R. (2017). When Sex and Gender Collide. Scientific American. https://doi.org/10.1038/scientificamerican0917-44

Phelps, S. M., \& Wedow, R. (2019). What Genetics Is Teaching Us about Sexuality. New York Times.

Pinker, S. (2002). The Blank Slate: The Modern Denial of Human Nature. New York: Viking Penguin.

Pinker, S. (2013). Science Is Not Your Enemy. The New Republic.

Plomin, R., \& von Stumm, S. (2018). The New Genetics of Intelligence. Nature Reviews: Genetics, 19, 148-159. https://www.gwern.net/docs/iq/2018-plomin.pdf https://doi.org/10.1038/nrg.2017.104

Schafer, A. (2006). https://genetics.thetech.org/ask/ask166

Sheldrake, R. (2012a). The Presence of the Past. Rochester: Park Street Press.

Sheldrake, R. (2012b). Science Set Free: 10 Paths to New Discovery. New York: Deepak Chopra Books.

Sohail, M., Maier, R. M., Ganna, A., Bloemendal, A., Martin, A. R., Turchin, M. C., Chiang, C. W. K., Hirschhorn, J., Daly, M. J., Patterson, N., Neale, B., Mathieson, I., Reich, D., \& Sunyaev, S. R. (2019). Polygenic Adaptation on Height Is Overestimated Due to Uncorrected Stratification in Genome Wide Association Studies. eLife.

https://reich.hms.harvard.edu/sites/reich.hms.harvard.edu/files/inline-files/2019 Sohai 1Maier eLife Height.pdf https://doi.org/10.7554/eLife.39702

Sokol, J. (2021). What Animals See in the Stars, and What They Stand to Lose. New York Times.

Solomon, A. (2012). Far from the Tree. New York: Scribner.

Stevenson, I. (1997). Where Reincarnation and Biology Intersect. Westport: Praeger Publishers.

Stevenson, I. (2000). The Phenomenon of Claimed Memories of Previous Lives: Possible Interpretations and Importance. Medical Hypotheses, 54, 652-659. https://pdfs.semanticscholar.org/e8d7/78d20507be2d971858ffeac47ad455c6ad95.pdf https://doi.org/10.1054/mehy.1999.0920

Treffert, D. A. (2010). Islands of Genius. London: Jessica Kingsley Publishers.

Tucker, J. (2005). Life before Life-A Scientific Investigation of Children's Memories of Previous Lives. New York: St. Martin's Press. 
Venter, J. C. (2007). A Life Decoded: My Genome: My Life. New York: Viking Adult.

Venter, J. C. (2014). Life at the Speed of Light: From the Double Helix to the Dawn of Digital Life. New York: Penguin Books.

Wade, N. (2008). A Dissenting Voice as the Genome Is Sifted to Fight Disease. New York Times.

Watson, J. D. (2003). A Conversation with James D. Watson. Scientific American.

Watson, J. D., Berry, A., \& Davies, K. (2017). DNA: The Story of the Genetic Revolution. New York: Albert A. Knopf.

Zimmer, C. (2015). Is Most of Our DNA Garbage? New York Times Magazine. 